\title{
HIF1A Overexpression Is Associated with Poor Prognosis in a Cohort of 731 Colorectal Cancers
}

\author{
Yoshifumi Baba, ${ }^{*}$ Katsuhiko Nosho, ${ }^{*}$ \\ Kaori Shima, ${ }^{*}$ Natsumi Irahara, ${ }^{*}$ Andrew T. Chan, ${ }^{\dagger}$ \\ Jeffrey A. Meyerhardt, ${ }^{*}$ Daniel C. Chung, ${ }^{\dagger}$ \\ Edward L. Giovannucci, ${ }^{\ddagger \S}$ Charles S. Fuchs, ${ }^{\star \ddagger}$ \\ and Shuji Ogino*ף

\begin{abstract}
From the Department of Medical Oncology,* Dana-Farber Cancer Institute and Harvard Medical School, Boston; the Gastrointestinal Boston; the Channing Laboratory, Department of Medicine, and the Department of Pathology, "Brigham and Women's Hospital and Harvard Medical School, Boston; and the Department of Epidemiology and Nutrition, ${ }^{\S}$ Harvard School of Public Health,
\end{abstract} \\ Unit, ${ }^{\dagger}$ Massachusetts General Hospital and Harvard Medical School, \\ Boston, Massachusetts
}

Tissue hypoxia commonly occurs in tumors. Hypoxiainducible factor (HIF)-1 and HIF-2, which are essential mediators of cellular response to hypoxia, regulate gene expression for tumor angiogenesis, glucose metabolism, and resistance to oxidative stress. Their key regulatory subunits, HIF1A (HIF-1 $\alpha$ ) and endothelial PAS domain protein 1 (EPAS1; HIF-2 $\alpha$ ), are overexpressed and associated with patient prognosis in a variety of cancers. However, prognostic or molecular features of colon cancer with HIF expression remain uncertain. Among 731 colorectal cancers in two prospective cohort studies, 142 (19\%) tumors showed HIF1A overexpression, and 322 (46\%) showed EPAS1 overexpression by immunohistochemistry. HIF1A overexpression was significantly associated with higher colorectal cancer-specific mortality in KaplanMeier analysis (log-rank test, $P<0.0001)$, univariate Cox regression (hazard ratio $=1.84 ; 95 \%$ confidence interval, 1.37 to $2.47 ; P<0.0001$ ) and multivariate analysis (adjusted hazard ratio $=1.72 ; 95 \%$ confidence interval, 1.26 to $2.36 ; P=0.0007$ ) that adjusted for clinical and tumoral features, including microsatellite instability, TP53 (p53), PTGS2 (cyclooxygenase-2), CpG island methylator phenotype, and KRAS, BRAF, PIK3CA, and LINE-1 methylation. In contrast, EPAS1 expression was not significantly associated with patient survival. In addition, HIF1A expression was independently associated with PTGS2 expression ( $P=$ 0.0035), CpG island methylator phenotype-high ( $P=$
0.013), and LINE-1 hypomethylation ( $P=0.017)$. EPAS1 expression was inversely associated with high tumor grade $(P=0.0017)$ and obesity (body mass index $\geq 30$ $\left.\mathrm{kg} / \mathrm{m}^{2}\right)(P=0.039)$. In conclusion, HIF1A expression is independently associated with poor prognosis in colorectal cancer, suggesting HIF1A as a biomarker with potentially important therapeutic implications. (Am J Pathol 2010, 176:2292-2301; DOI: 10.2353/ajpath.2010.090972)

Tissue hypoxia commonly occurs in tumor, and adaptation to tissue hypoxia appears to be one of important characteristics of malignant cells. ${ }^{1,2}$ Hypoxia-inducible factor (HIF)-1 and HIF-2 play a key role in cellular adaptation to hypoxia and regulate the expression of genes responsible for glucose metabolism, angiogenesis, and cell survival. ${ }^{1-3}$ Thus, HIF and related pathways are potential therapeutic targets. ${ }^{4,5}$ Cellular HIF levels are regulated not only by the oxygen-dependent pathway (eg, VHL and prolyl hydroxylase, EGLN) but also by the oxygen-independent pathway (eg, glycogen synthase kinase 3, the phosphatidylinositol 3-kinase pathway, the mitogen-activated protein kinase kinase/extracellular signal-regulated kinase pathway). ${ }^{6,7}$ HIF and hypoxia signaling influence a wide variety of pathways including those related to vascular endothelial growth factor (VEGF), cyclins, and MTOR. ${ }^{1,2}$ Thus, cellular HIF levels may modify responsiveness to drugs targeting those pathways or hypoxia signaling, and it is of particular

Supported by U.S. National Institute of Health grants P01 CA87969 (to S. Hankinson), P01 CA55075 (to W. Willett), P50 CA127003 (to C.S.F.), K07 CA107412 (to A.T.C.), and K07 CA122826 (to S.O.) and in part by grants from the Bennett Family Fund and from the Entertainment Industry Foundation National Colorectal Cancer Research Alliance. K.N. was supported by a fellowship grant from the Japan Society for Promotion of Science. In addition, A.T.C. was supported by a grant from the Damon Runyon Cancer Research Foundation.

Y.B., K.N., and K.S. contributed equally.

Accepted for publication January 5, 2010.

Address reprint requests to Shuji Ogino, M.D., Ph.D., Center for Molecular Oncologic Pathology, Dana-Farber Cancer Institute, Brigham and Women's Hospital, Harvard Medical School, 44 Binney St., Room JF215C, Boston, MA 02115. E-mail: shuji_ogino@dfci.harvard.edu. 
interest to examine HIF expression in human cancers. Key regulatory subunits of HIF, HIF1A (the official symbol for HIF-1 $\alpha$ ), and endothelial PAS domain protein 1 (EPAS1; the official symbol for HIF-2 $\alpha$ ) are differentially overexpressed $^{8,9}$ and have distinct functions in human cancers. ${ }^{9-11}$ HIF1A expression leads to increased tumor growth and metastasis in some studies, ${ }^{12-15}$ whereas HIF1A inhibits tumor growth by cell cycle arrest or apoptosis induction in other studies. ${ }^{16-19}$ Similar paradoxical effects of EPAS1 have also been reported; EPAS1 appears to promote cancer development and progression in neuroblastoma and renal carcinoma, ${ }^{20-22}$ whereas it appears to inhibit tumor growth in other cancers including colon cancer. ${ }^{23-25}$

Previous data on HIF1A, EPAS1, and clinical outcome in colorectal cancer have been inconclusive. A study of 90 rectal cancer patients showed poor prognosis associated with HIF1A but not with EPAS1. ${ }^{26}$ In contrast, another study of 87 colorectal cancer patients reported poor prognosis associated with EPAS1 but not with HIF1A. ${ }^{27}$ Among studies assessing only HIF1A, some reported its independent prognostic effect ${ }^{28,29}$ whereas others did not. ${ }^{30,31}$ However, all previous studies ${ }^{26-31}$ were limited by small sample sizes $(N<136)$. Considering the increasing importance of the HIF pathway as a potential target for cancer treatment, ${ }^{1,2,6}$ the assess- ment of HIF1A and EPAS1 expression and clinical outcome using a large number of colorectal cancers is needed.

We therefore examined prognostic effects of HIF1A and EPAS1 expression among 731 colorectal cancer patients identified in two prospective cohort studies. Moreover, because we concurrently assessed other important molecular events including mutations in KRAS, $B R A F$, and PIK3CA, LINE-1 hypomethylation, microsatellite instability (MSI), and the $\mathrm{CpG}$ island methylator phenotype (CIMP), we could evaluate the effect of HIF1A or EPAS1 expression after controlling for these potential confounders.

\section{Materials and Methods}

\section{Study Group}

We used the databases of two independent, prospective cohort studies: the Nurses' Health Study $(N=121,701$ women followed since 1976) $)^{32}$ and the Health Professionals Follow-Up Study ( $N=51,529$ men followed since 1986). ${ }^{32}$ We collected paraffin-embedded tissue blocks from hospitals where patients with incident colorectal cancers underwent tumor resections. ${ }^{32}$ We excluded

Table 1. Clinical and Pathologic Features according to HIF1A Expression or EPAS1 (HIF-2 $\alpha$ ) Expression Status

\begin{tabular}{|c|c|c|c|c|c|c|c|}
\hline \multirow[b]{2}{*}{ Clinical or pathologic feature } & \multirow[b]{2}{*}{ Total $(N)$} & \multicolumn{2}{|c|}{ HIF1A expression } & \multirow[b]{2}{*}{$P$ value } & \multicolumn{2}{|c|}{ EPAS1 expression } & \multirow[b]{2}{*}{$P$ value } \\
\hline & & $(-)$ & $(+)$ & & $(-)$ & $(+)$ & \\
\hline All cases & 731 & 589 & 142 & & 373 & 322 & \\
\hline Sex & & & & 0.058 & & & 0.0043 \\
\hline Male (HPFS) & 261 & $220(37 \%)$ & $41(29 \%)$ & & $112(30 \%)$ & $130(40 \%)$ & \\
\hline Female (NHS) & 470 & 369 (63\%) & $101(71 \%)$ & & 261 (70\%) & $192(60 \%)$ & \\
\hline \multicolumn{8}{|l|}{ Age $(y r)$} \\
\hline$\leq 59$ & 148 & $116(20 \%)$ & $32(23 \%)$ & 0.74 & $80(21 \%)$ & $56(17 \%)$ & 0.40 \\
\hline $60-69$ & 307 & $250(42 \%)$ & $57(40 \%)$ & & $152(41 \%)$ & $139(43 \%)$ & \\
\hline$\geq 70$ & 276 & $223(38 \%)$ & $53(37 \%)$ & & $141(38 \%)$ & $127(40 \%)$ & \\
\hline BMI & & & & 0.90 & & & 0.021 \\
\hline$<30 \mathrm{~kg} / \mathrm{m}^{2}$ & 604 & $487(83 \%)$ & $117(82 \%)$ & & 297 (80\%) & $277(86 \%)$ & \\
\hline$\geq 30 \mathrm{~kg} / \mathrm{m}^{2}$ & 126 & $101(17 \%)$ & $25(18 \%)$ & & $76(20 \%)$ & $44(14 \%)$ & \\
\hline \multirow{3}{*}{ Family history of colorectal cancer } & & & & 0.40 & & & 0.48 \\
\hline & 560 & $455(77 \%)$ & $105(74 \%)$ & & $290(78 \%)$ & $243(75 \%)$ & \\
\hline & 171 & $134(23 \%)$ & $37(26 \%)$ & & $83(22 \%)$ & $79(25 \%)$ & \\
\hline \multicolumn{2}{|l|}{ Tumor location } & & & 0.80 & & & 0.21 \\
\hline Proximal colon (cecum to transverse) & 361 & $294(51 \%)$ & $67(48 \%)$ & & $184(50 \%)$ & $159(50 \%)$ & \\
\hline Distal colon (splenic flexure to sigmoid) & 214 & $172(30 \%)$ & $42(30 \%)$ & & $100(27 \%)$ & $100(32 \%)$ & \\
\hline Rectum & 142 & $112(19 \%)$ & $30(22 \%)$ & & $83(23 \%)$ & $56(18 \%)$ & \\
\hline \multicolumn{2}{|l|}{ Stage } & & & 0.069 & & & 0.28 \\
\hline I & 160 & $140(24 \%)$ & $20(14 \%)$ & & $74(20 \%)$ & $82(26 \%)$ & \\
\hline II & 222 & $180(31 \%)$ & $42(30 \%)$ & & $110(29 \%)$ & $101(31 \%)$ & \\
\hline III & 200 & $157(27 \%)$ & $43(30 \%)$ & & $110(29 \%)$ & $77(24 \%)$ & \\
\hline IV & 108 & 77 (13\%) & $31(22 \%)$ & & $58(16 \%)$ & $44(14 \%)$ & \\
\hline Unknown & 41 & $35(5.9 \%)$ & $6(4.2 \%)$ & & $21(5.6 \%)$ & $18(5.6 \%)$ & \\
\hline \multicolumn{2}{|l|}{ Tumor grade } & & & 0.36 & & & 0.0016 \\
\hline Low & 660 & $535(91 \%)$ & $125(89 \%)$ & & $325(88 \%)$ & $305(95 \%)$ & \\
\hline High & 68 & $52(8.9 \%)$ & $16(11 \%)$ & & $45(12 \%)$ & $17(5.3 \%)$ & \\
\hline \multicolumn{2}{|l|}{ Mucinous component } & & & 0.26 & & & 0.11 \\
\hline $0 \%$ & 373 & $297(57 \%)$ & $76(62 \%)$ & & $196(60 \%)$ & $157(54 \%)$ & \\
\hline$>0 \%$ & 272 & $226(43 \%)$ & $46(38 \%)$ & & $128(40 \%)$ & $133(46 \%)$ & \\
\hline \multirow{3}{*}{$\begin{array}{l}\text { Signet ring cell component } \\
\quad 0 \% \\
>0 \%\end{array}$} & & & & 0.24 & & & 0.16 \\
\hline & 549 & $443(89 \%)$ & $106(93 \%)$ & & $272(88 \%)$ & $250(92 \%)$ & \\
\hline & 61 & $53(11 \%)$ & $8(7.0 \%)$ & & $37(12 \%)$ & $23(8.4 \%)$ & \\
\hline
\end{tabular}

Percentage indicates the proportion of tumors with a specific clinical or pathologic feature in all patients or patients with a specific category of HIF1A or EPAS1 expression status. HPFS, Health Professionals Follow-Up Study; NHS, Nurses' Health Study. 
cases preoperatively treated with radiation and/or chemotherapy. On the basis of availability of adequate tissue specimens and follow-up data, a total of 731 colorectal cancers (diagnosed up to 2004) were included (Table 1). Patients were observed until death or June 2008, whichever came first. Among our cohort studies, there was no significant difference in demographic features between cases with tissue available and those without available tissue. $^{32}$ Tissue sections from all cases were reviewed by a pathologist (S.O.) unaware of other data. The tumor grade was categorized as low versus high ( $\geq 50$ versus $<50 \%$ gland formation). This current analysis represents a new analysis of HIF1A and EPAS1 on the existing colorectal cancer database that has been previously characterized for CIMP, MSI, LINE-1 methylation, and clinical outcome, ${ }^{32-35}$ which is analogous to novel studies using the well-described cell lines or animal models. We have not examined HIF1A or EPAS1 expression in any of our previous studies. Written informed consent was obtained from all study subjects. Tissue collection and analyses were approved by the Harvard School of Public Health and Brigham and Women's Hospital Institutional Review Boards.

\section{Sequencing of KRAS, BRAF, and PIK3CA and MSI Analysis}

Genomic DNA was extracted from tumor and PCR and Pyrosequencing targeted for KRAS (codons 12 and 13), ${ }^{36}$ BRAF (codon 600), ${ }^{37}$ and PIK3CA (exons 9 and $20)^{38}$ were performed. MSI status was determined using D2S123, D5S346, D17S250, BAT25, BAT26, BAT40, D18S55, D18S56, D18S67, and D18S487. ${ }^{39} \mathrm{MSI}$-high was defined as the presence of instability in $\geq 30 \%$ of the markers, MSI-low as instability in 1 to $29 \%$ of the markers, and microsatellite stability (MSS) as the absence of unstable markers. ${ }^{35}$

\section{Methylation Analyses for CpG Islands and LINE-1}

Bisulfite DNA treatment and real-time PCR (MethyLight) were validated and performed. ${ }^{40}$ We quantified DNA methylation in eight CIMP-specific promoters [CACNA1G, CDKN2A (p16), CRABP1, IGF2, MLH1, NEUROG1, RUNX3, and SOCS1]. ${ }^{35,41,42}$ CIMP-high was defined as the presence of $\geq 6 / 8$ methylated promoters, CIMP-low as $1 / 8$ to $5 / 8$ methylated promoters, and CIMP-0 as the absence $(0 / 8)$ of methylated promoters, according to the previously established criteria. ${ }^{35}$

To accurately quantify relatively high methylation levels in LINE-1 repetitive elements, we used Pyrosequencing as described previously. ${ }^{43}$

\section{Immunohistochemistry}

Tissue microarray blocks were constructed. ${ }^{44}$ Methods of immunohistochemistry for TP53 and PTGS2 (cyclooxygenase-2, COX-2) were described previously. ${ }^{32,39,45}$ Appropriate positive and negative controls were included in every run of immunohistochemistry. For HIF1A staining (Figure 1), deparaffinized tissue sections in Antigen Retrieval Citra Solution (Biogenex Laboratories, San Ramon, CA) were treated with microwave (15 minutes). Tissue sections were incubated with 5\% normal goat serum (Vector Laboratories, Burlingame, CA) in PBS (30 minutes). Primary antibody [rabbit polyclonal anti-HIF-1 $\alpha(\mathrm{H}-$ 206), 1/500 dilution; Santa Cruz Biotechnology, Santa Cruz, CA] was applied at $4^{\circ} \mathrm{C}$ for overnight, followed by rabbit secondary antibody (Vector Laboratories) (30 minutes), an avidin-biotin complex conjugate (Vector Laboratories) (30 minutes), diaminobenzidine (5 minutes), and methyl-green counterstain. Cytoplasmic HIF1A expression was recorded as no, weak, moderate, or strong expression with the percentage of positive tumor cells (Figure 1). Among the 731 tumors, 200 tumors showed no HIF1A expression, 345 showed weak expression, 176 showed moderate expression, and 10 showed strong expression. The percentage of HIF1A-positive tumor cells ranged from 0 to $90 \%$ (median, 30\%).

In our initial exploratory analysis, we randomly selected 366 tumors as a training set and classified the training set tumors according to the intensity and extent of HIF1A expression. In the training set, the adjusted hazard ratio (HR) for colorectal cancer-specific mortality in each category (compared with tumors with no expres-

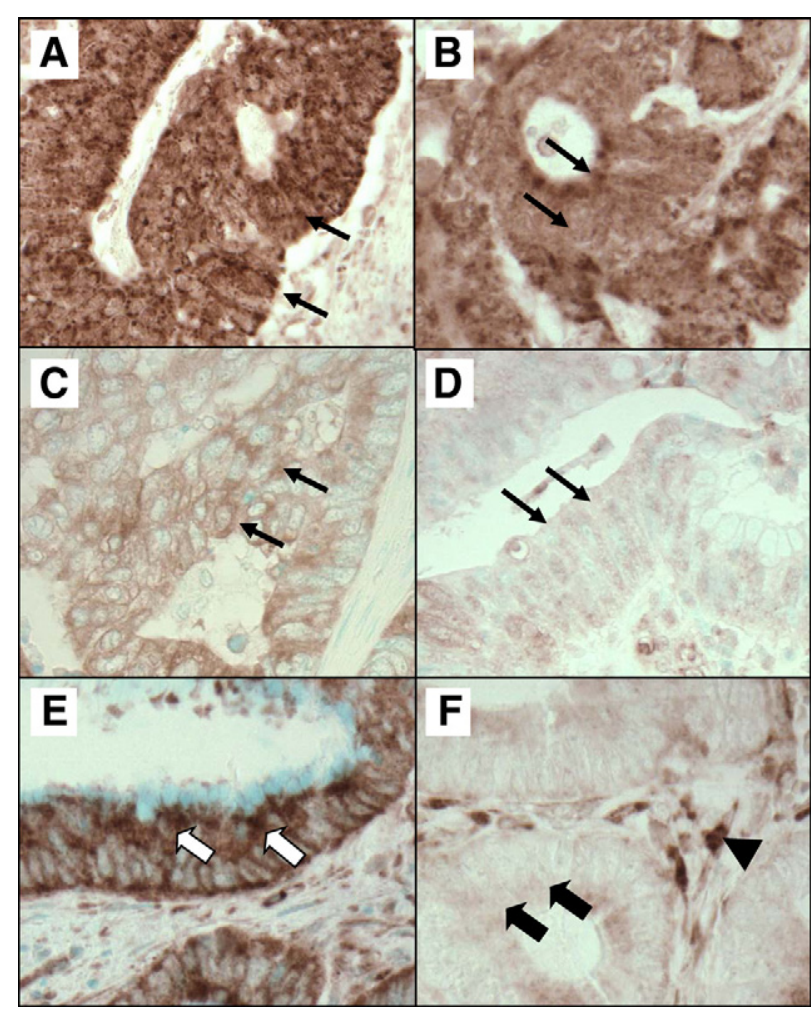

Figure 1. HIF1A expression and EPAS1 (HIF-2 $\alpha$ ) expression in colon cancer. A: Strong expression of HIF1A in cytoplasm of colon cancer cells (arrows). B: Moderate expression of HIF1A in cytoplasm of colon cancer cells (arrows). C: Weak expression of HIF1A in cytoplasm of colon cancer cells (arrows). D: No overexpression of HIF1A in colon cancer cells (arrows). E: EPAS1 overexpression in cytoplasm of colon cancer cells (white arrows). F: No expression of EPAS1 in colon cancer cells (black arrows) Stromal cells serve as an internal positive control for EPAS1 expression (arrowhead) 
sion) was as follows: 0.90 [95\% confidence interval (Cl), 0.58 to 1.38 ] in tumors with weak expression; 0.93 (95\% $\mathrm{Cl}, 0.44$ to 1.96$)$ in tumors with moderate expression in 1 to $49 \%$ cells; and 1.98 (95\% Cl, 1.04 to 3.77 ) in tumors with moderate expression in $\geq 50 \%$ cells or strong expression. Thus, HIF1A positivity was defined as the presence of moderate cytoplasmic staining in $\geq 50 \%$ of tumor cells or strong expression in any fraction of tumor cells. Kaplan-Meier analysis according to HIF1A status was performed on the training set $(N=366)$ and the remaining validation set $(N=365)$, and results were very similar (all log-rank test, $P<0.05$; Figure 2, A and B), confirming the validity of our criteria for HIF1A positivity.

For EPAS1 staining (Figure 1), the same protocol with HIF1A was used except for primary antibody against EPAS1 (mouse monoclonal anti-EPAS-1, 1/250 dilution; Santa Cruz Biotechnology) and mouse secondary antibody. Cytoplasmic EPAS1 expression was recorded as no, weak, moderate, or strong expression. Among the 695 tumors, 373 tumors showed no EPAS1 expression, 176 showed weak expression, 132 showed moderate expression, and 14 showed strong expression. In our initial exploratory analysis, the frequency of high tumor grade, which was most significantly related with EPAS1 expression, in each category was as follows: $12.3 \%$ (46 of 373 ) in tumors with no expression; $4.5 \%$ (8 of 176 ) in tumors with weak expression; 6.8\% (9 of 132) in tumors with moderate expression; and 0\% (0 of 14) in tumors with strong expression. Thus, for further analysis, EPAS1 positivity was defined as weak to strong cytoplasmic expression.
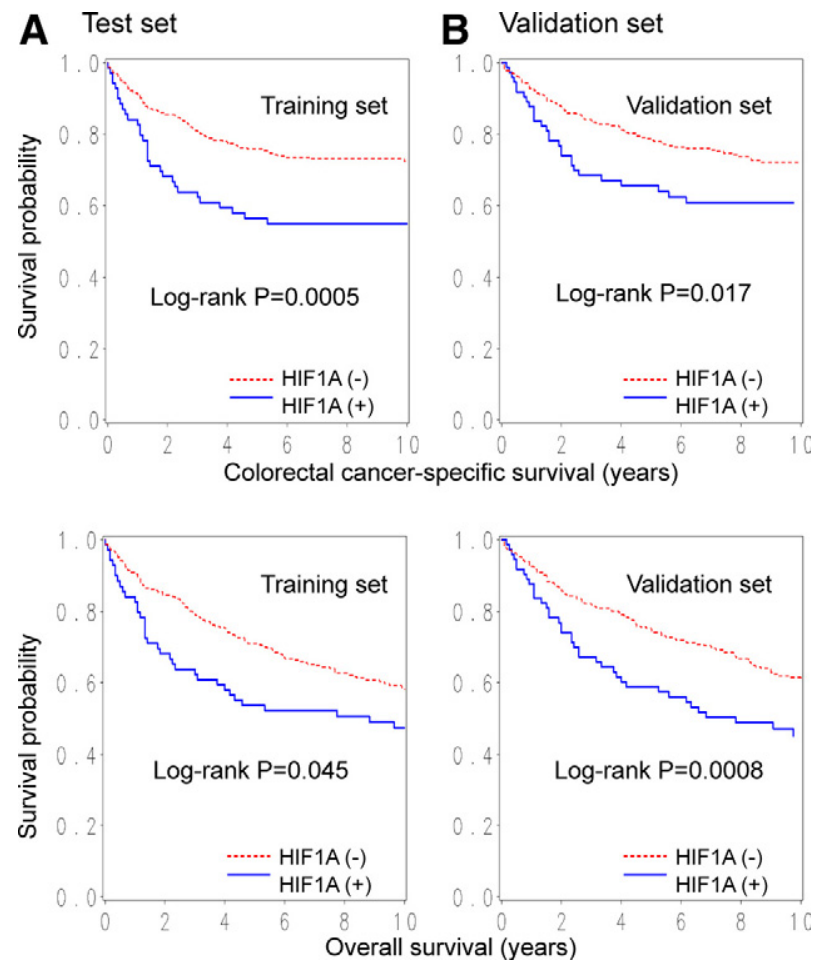

Log-rank $P=0.017$

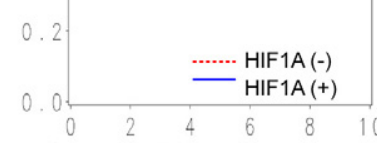

pecific survival (years)

Figure 2. Kaplan-Meier curves for colorectal cancer-specific survival (top panels) and overall survival (bottom panels) according to HIF1A status in colorectal cancer on the training set (left panels, $N=366$ ) (A) and the validation set (right panels, $N=365)(\mathbf{B})$.
Each immunohistochemical maker was visually interpreted by one of the investigators (HIF1A and EPAS1 by Y.B.; TP53 and PTGS2 by S.O.) unaware of other data. A random selection of 108 to 193 cases was examined for each marker by a second pathologist (HIF1A, EPAS1, and TP53 by K.N., PTGS2 by R. Dehari, Kanagawa Cancer Center Yokohama, Japan) unaware of other data. The concordance between the two observers was $0.88(\kappa=$ $0.60, P<0.0001, N=193)$ for HIF1A, $0.87(\kappa=0.74, P<$ $0.0001, N=143)$ for EPAS1, $0.87(\kappa=0.75, P<0.0001$, $N=108)$ for TP53, and $0.92(\kappa=0.62, P<0.0001, N=$ 108) for PTGS2, indicating substantial agreement.

\section{Statistical Analysis}

For all statistical analyses, we used SAS program (version 9.1; SAS Institute, Cary, NC). All $P$ values were two-sided, and statistical significance was set at $P \leq$ 0.05 . Nonetheless, when we performed multiple hypothesis testing, a $P$ value for significance was adjusted by Bonferroni correction to $P=0.0033$. For categorical data, the $\chi^{2}$ test was performed. To assess independent relations of HIF1A or EPAS1 expression with other variables, a multivariate logistic regression analysis was performed, initially including sex, age at diagnosis (continuous), body mass index (BMl $<30$ versus $\left.\geq 30 \mathrm{~kg} / \mathrm{m}^{2}\right)$, family history of colorectal cancer in any first degree relative (present versus absent), tumor location (rectum versus
A
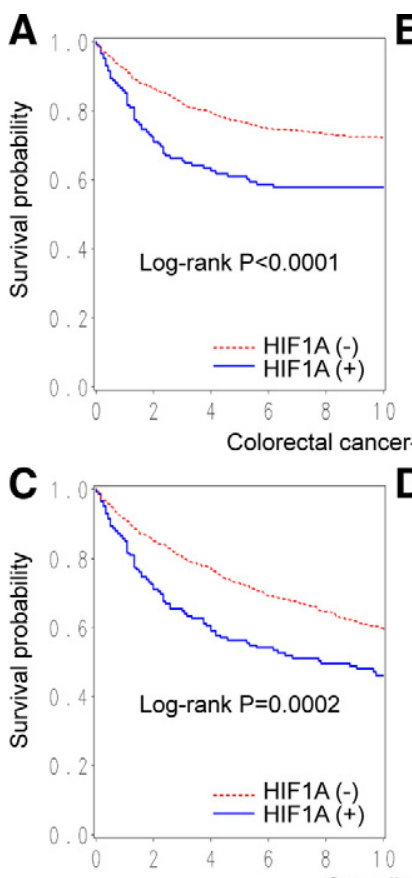

Overall survival (years)
B

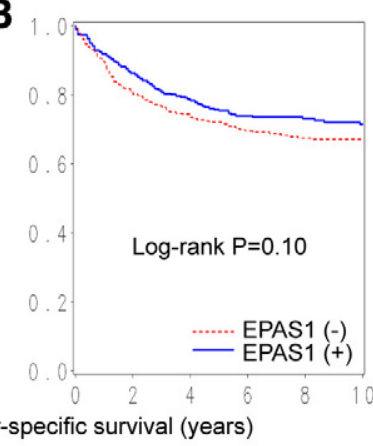

D

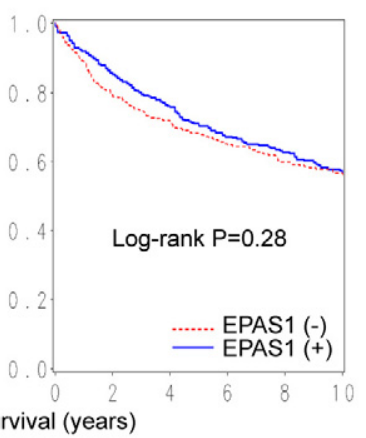

Number at risk

\begin{tabular}{|c|c|c|c|c|c|c|c|c|c|c|c|c|c|}
\hline Year & 0 & 2 & 4 & 6 & 8 & 10 & \multirow{2}{*}{$\begin{array}{c}\text { Year } \\
\text { EPAS1 (-) }\end{array}$} & 0 & 2 & 4 & 6 & 8 & 10 \\
\hline $\mathrm{H} F$ & 589 & 502 & 454 & 375 & 290 & 215 & & 373 & 297 & 267 & 230 & 179 & 141 \\
\hline $1 \mathrm{~A}$ & 142 & 102 & 85 & 72 & 63 & 46 & EPAS1 (+) & 322 & 275 & 243 & 191 & 151 & 105 \\
\hline
\end{tabular}

Figure 3. Kaplan-Meier curves for colorectal cancer-specific survival (A and B) and overall survival (C and D) according to HIF1A status (A and $\mathbf{C}$ ) or EPAS1 (HIF-2 $\alpha$ ) status (B and D) in colorectal cancer. Tables indicate the number of patients who were alive and at risk of death at each time point after the diagnosis of colorectal cancer. 
colon), tumor stage (I-III versus IV), tumor grade (low versus high), mucinous component ( 0 versus $>0 \%$ ), signet ring cell component ( 0 versus $>0 \%$ ), CIMP (high versus low/0), MSI (high versus low/MSS), LINE-1 methylation (continuous), and BRAF, KRAS, PIK3CA, TP53, and PTGS2, using patients $(N=511)$ with available molecular data. Backward stepwise elimination with a threshold of $P=0.20$ was used to select variables in the final model. For cases with missing information in any of categorical variables [BMI (0.1\%), tumor location (1.9\%), tumor grade $(0.4 \%)$, CIMP (3.3\%), MSI $(0.6 \%)$, BRAF (3.1\%), KRAS (0.6\%), PIK3CA (12\%), TP53 (0.8\%), and PTGS2 (0.6\%)], we included those cases in a majority category of that missing variable in the initial model. After the selection was done, we assigned separate missing indicator variables to those cases with missing information in any of the categorical covariates in the final model. We confirmed that excluding cases with missing information in any of the covariates did not substantially alter results (data not shown).

For survival analysis, Kaplan-Meier method was used to assess survival time distribution, and log-rank test was used. For analyses of colorectal cancer-specific mortality, deaths as a result of causes other than colorectal cancer were censored. To assess independent effect of HIF1A or EPAS1 on mortality, tumor stage (I, IIA, IIB, IIIA, IIIB, IIIC, IV, unknown) was used as a stratifying (matching) variable in Cox models using the "strata" option in the SAS "proc phreg" command to avoid residual confounding and overfitting. We constructed a multivariate, stage-matched (stratified) Cox proportional hazard model to compute a HR according to HIF1A or EPAS1 status, initially containing sex, age at diagnosis, BMI, family history of colorectal cancer, year of diagnosis, tumor location, tumor grade, mucinous component, and signet ring cell component. Backward stepwise elimination with a threshold of $P=0.20$ was used to select variables in the final model. In addition, using patients $(N=511)$ with available data on molecular features, a multivariate model containing CIMP, MSI, BRAF, KRAS, PIK3CA, LINE-1 methylation, TP53, and PTGS2 was also performed. The proportionality of hazard assumption was satisfied by evaluating time-dependent variables, which were the cross-product of the HIF1A (or EPAS1) variable and survival time $(P>0.31)$. An interaction was assessed by including the cross-product of HIF1A (or EPAS1) variable and another variable of interest (without data-missing cases) in a multivariate Cox model, and the Wald test was performed.

\section{Results}

\section{HIF1A Expression in Colorectal Cancer}

In our initial exploratory analysis, as described in detail in Materials and Methods, we defined the criteria for HIF1A positivity based on the relation with colorectal cancerspecific mortality on the training set $(N=366)$. KaplanMeier analysis according to HIF1A status was performed on the training set $(N=366)$ and the remaining validation set $(N=365)$, and results were very similar (all log-rank test, $P<0.05$; Figure 2), confirming the validity of our criteria for HIF1A positivity.

Among 731 colorectal cancers, we observed HIF1A overexpression in 142 tumors (19\%) by immunohistochemistry. Tables 1 and 2 show the frequency of HIF1A overexpression in relation to various clinical, pathological, and molecular features.

We performed multivariate logistic regression analysis. In multivariate analysis, HIF1A expression was associated with PTGS2 expression [adjusted odds ratio (OR), 2.11; $95 \% \mathrm{Cl}, 1.28$ to $3.43 ; P=0.0035$ ), CIMP-high (adjusted OR, 2.72; 95\% Cl, 1.24 to 6.00; $P=0.013$ ), and LINE-1 hypomethylation (for a $30 \%$ decrease; adjusted OR, 2.51; 95\% Cl, 1.18 to $5.35 ; P=0.017$ ) (Table 3), although any of these might be a chance association $[P=0.0033(=0.05 / 15)$ was necessary for statistical significance by Bonferroni correction, given multiple hypothesis testing].

\section{EPAS1 (HIF-2 $\alpha$ ) Expression in Colorectal Cancer}

EPAS1 expression was observed in 322 tumors (46\%) by immunohistochemistry. EPAS1 expression was related inversely with high tumor grade $(P=0.0016)$ (Table 1). EPAS1 expression was not significantly associated with any molecular feature (Table 2).

In multivariate logistic regression analysis, EPAS1 expression was inversely with high tumor grade [adjusted odds ratio, $0.39 ; 95 \% \mathrm{Cl}, 0.22$ to $0.70 ; P=$ 0.0017] (Table 3).

\section{HIF1A Expression and Patient Survival}

During follow-up of 731 patients, there were 344 deaths, including 221 deaths attributed to colorectal cancer. In Kaplan-Meier analysis, HIF1A expression was significantly associated with shorter colorectal cancer-specific survival (log-rank test, $P<0.0001$ ) and overall survival (log-rank test, $P=0.0002$ ) (Figure 3, A and C). Five-year colorectal cancer-specific survival was $76.9 \%(95 \% \mathrm{Cl}$, 73.3 to $80.1 \%$ ) among HIF1A-negative case and $60.3 \%$ (95\% Cl, 51.7 to $67.8 \%$ ) among HIF1A-positive cases. Five-year overall survival was $72.6 \%(95 \% \mathrm{Cl}, 68.8$ to $76.0 \%)$ among HIF1A-negative cases, and 55.6\% (95\% $\mathrm{Cl}, 47.1$ to $63.3 \%$ ) among HIF1A-positive cases.

In univariate Cox regression analysis, compared with HIF1A-negative cases, HIF1A-positive cases experienced a significantly higher colorectal cancer-specific mortality (HR 1.84; 95\% Cl, 1.37 to $2.47 ; P<0.0001$ ) (Table 4). In the multivariate Cox model adjusting for clinical and pathological features, HIF1A overexpression was associated with a significantly higher colorectal cancer-specific mortality (multivariate HR $1.72 ; 95 \% \mathrm{Cl}, 1.26$ to $2.36 ; P=0.0007$ ) (Table 4). No major confounder was present. In the multivariate Cox model that included additional molecular variables including KRAS, BRAF, PIK3CA, PTGS2, TP53, LINE-1 hypomethylation, MSI, and CIMP, similar results were obtained (multivariate HR, 
Table 2. Molecular Features according to Expression Status of HIF1A or EPAS1 (HIF-2 $\alpha$ )

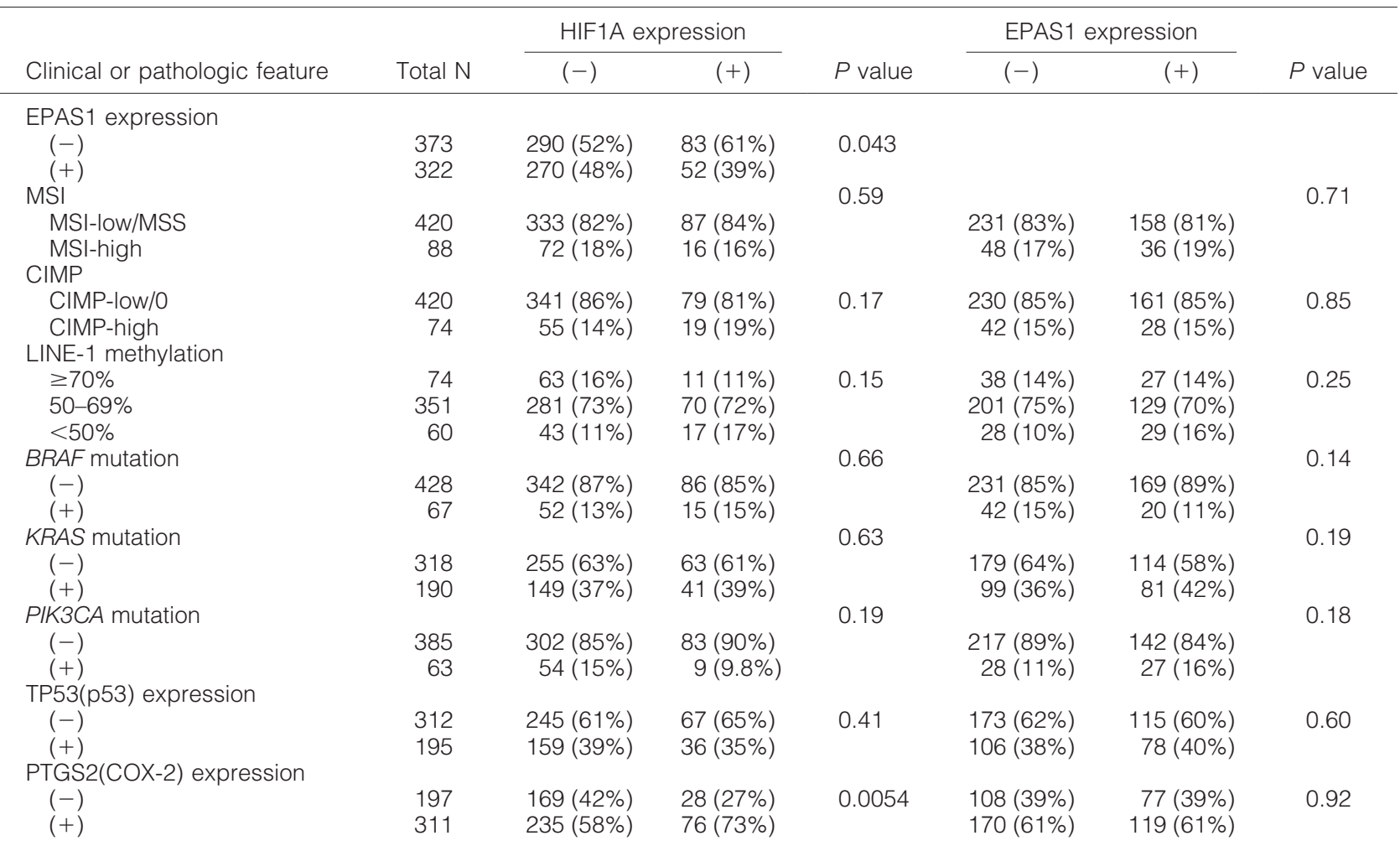

Percentage indicates the proportion of tumors with a specific clinical or pathologic feature in all patients or patients with a specific category of HIF1A or EPAS1 expression status.

$1.94 ; 95 \% \mathrm{Cl}, 1.31$ to $2.87 ; P=0.0009)$. Again, no major confounder was present among the molecular variables. Analyses using overall mortality yielded similar, although attenuated, results (Table 4).

Table 3. Multivariate Analysis of the Relationship with HIF1A or EPAS1 (HIF-2a) in Colorectal Cancer

\begin{tabular}{ccc}
\hline & $\begin{array}{c}\text { Multivariate OR } \\
(95 \% \mathrm{Cl})\end{array}$ & $\begin{array}{c}P \\
\text { value }\end{array}$ \\
\hline $\begin{array}{c}\text { Variables in the final model for } \\
\text { HIF1A }\end{array}$ & & \\
PTGS2(COX-2) expression & $2.11(1.28-3.43)$ & 0.0035 \\
CIMP-high (vs. CIMP-low/0) & $2.72(1.24-6.00)$ & 0.013 \\
LINE-1 hypomethylation (for & $2.51(1.18-5.35)$ & 0.017 \\
a 30\% decrease) & $1.54(0.95-2.49)$ & 0.083 \\
Female sex & & \\
MSI-high (vs. MSI-low/MSS) & $0.50(0.22-1.11)$ & 0.088 \\
& & \\
Variables in the final model for & & \\
EPAS1 & $0.39(0.22-0.70)$ & 0.0017 \\
High tumor grade & $1.48(1.07-2.04)$ & 0.018 \\
Male sex & $0.65(0.43-0.98)$ & 0.039 \\
BMI $\geq 30 \mathrm{~kg} / \mathrm{m}^{2}$ & & \\
$\quad$ (vs. $\left.<30 \mathrm{~kg} / \mathrm{m}^{2}\right)$ & $1.38(0.99-1.91)$ & 0.057 \\
Mucinous component $>$ & & \\
0\% (vs. 0\%) & &
\end{tabular}

Multivariate logistic regression analysis assessing the relationship with HIF1A or EPAS1 (as an outcome variable) initially included age, sex, body mass index, tumor location, stage, tumor grade, mucinous component, signet ring cell component, microsatellite instability, CpG island methylator phenotype, PTGS2, TP53, KRAS, PIK3CA, and BRAF. Backward stepwise elimination with threshold of $P=0.20$ was used to select variables in the final model. A $P$ value for significance was adjusted by Bonferroni correction to $P=0.0033$.

\section{Stage-Specific Analysis of HIF1A Expression and Survival}

To evaluate a prognostic effect of HIF1A expression in each tumor stage, we examined stage-specific HR for HIF1A-positive tumors compared with HIF1A-negative tumors. Although statistical power was limited in subset analyses, prognostic influence of HIF1A expression seemed to be consistent across tumor stages ( $p$ for interaction $=0.35$ to 0.95$)$ (Table 5).

\section{Interaction between HIF1A and Another Variable in Survival Analyses}

We examined whether the influence of HIF1A expression on colorectal cancer-specific survival was modified by any of the clinical, pathological, and molecular variables. We did not observe a significant interaction between HIF1A expression and any of the covariates (all $\mathrm{P}_{\text {interaction }}>$ $0.24)$. Notably, there was no significant interaction between HIF1A and EPAS1 expression $\left(P_{\text {interaction }}=0.29\right)$. In addition, the effect of HIF1A did not significantly differ between the two independent cohort studies $\left(P_{\text {interaction }}=0.75\right)$.

\section{EPAS1 (HIF-2 $\alpha$ ) Expression and Patient Survival}

In the Kaplan-Meier analysis, there was no significant difference in survival time distributions according to 
Table 4. HIF1A or EPAS1 (HIF-2a) Expression in Colorectal Cancer and Patient Mortality

\begin{tabular}{|c|c|c|c|c|c|c|c|}
\hline & \multirow[b]{2}{*}{ Total N } & \multicolumn{3}{|c|}{ Colorectal cancer-specific mortality } & \multicolumn{3}{|c|}{ Overall mortality } \\
\hline & & $\begin{array}{c}\text { Deaths/ } \\
\text { person-years }\end{array}$ & $\begin{array}{c}\text { Univariate HR } \\
(95 \% \mathrm{Cl})\end{array}$ & $\begin{array}{c}\text { Multivariate HR } \\
(95 \% \mathrm{Cl})\end{array}$ & $\begin{array}{c}\text { Deaths/ } \\
\text { person-years }\end{array}$ & $\begin{array}{c}\text { Univariate HR } \\
(95 \% \mathrm{Cl})\end{array}$ & $\begin{array}{c}\text { Multivariate HR } \\
(95 \% \mathrm{Cl})\end{array}$ \\
\hline $\begin{array}{l}\text { HIF1A expression } \\
\qquad \begin{array}{l}(-) \\
(+)\end{array}\end{array}$ & $\begin{array}{l}589(81 \%) \\
142(19 \%)\end{array}$ & $\begin{array}{r}159 / 4973 \\
62 / 1057\end{array}$ & $\begin{array}{c}1 \text { (referent) } \\
1.84(1.37-2.47) \\
P<0.0001\end{array}$ & $\begin{array}{c}1 \text { (referent) } \\
1.72(1.26-2.36) \\
P=0.0007\end{array}$ & $\begin{array}{r}257 / 4973 \\
87 / 1057\end{array}$ & $\begin{array}{c}1 \text { (referent) } \\
1.59(1.25-2.03) \\
P=0.0002\end{array}$ & $\begin{array}{c}1 \text { (referent) } \\
1.50(1.16-1.94) \\
P=0.0021\end{array}$ \\
\hline $\begin{array}{l}\text { EPAS1 expression } \\
\qquad \begin{array}{l}(-) \\
(+)\end{array}\end{array}$ & $\begin{array}{l}373(54 \%) \\
322(46 \%)\end{array}$ & $\begin{array}{r}124 / 3066 \\
88 / 2624\end{array}$ & $\begin{array}{c}1 \text { (referent) } \\
0.80(0.61-1.05) \\
P=0.10\end{array}$ & $\begin{array}{c}1 \text { (referent) } \\
0.88(0.66-1.17) \\
P=0.39\end{array}$ & $\begin{array}{l}185 / 3066 \\
142 / 2624\end{array}$ & $\begin{array}{c}1 \text { (referent) } \\
0.89(0.71-1.10) \\
P=0.28\end{array}$ & $\begin{array}{c}1 \text { (referent) } \\
0.96(0.77-1.21) \\
P=0.74\end{array}$ \\
\hline
\end{tabular}

The multivariate, stage-matched conditional Cox regression model initially included age, year of diagnosis, sex, family history of colorectal cancer $\mathrm{BMI}$, tumor location, grade, mucinous component, and signet ring cell component. Backward stepwise elimination with threshold of $P=0.20$ was used to select variables in the final model.

EPAS1 status (log-rank test, $P \geq 0.10$ ) (Figure 3, B and D). In univariate or multivariate Cox regression analysis, EPAS1 expression was not significantly related with patient survival (Table 4).

\section{Discussion}

We examined the prognostic effect of HIF1A and EPAS1 (the official symbol for HIF-2 $\alpha$ ) expression among 731 colorectal cancer patients participating in two prospective cohort studies. HIFs are the critical molecular mediators in tissue hypoxia and have been targeted for cancer therapy. ${ }^{1,2,6}$ HIF and hypoxia signaling influence a wide variety of signaling pathways including cyclins, VEGF and MTOR. ${ }^{1,2}$ Thus, cellular HIF levels may modify responsiveness to drugs targeting those pathways or the hypoxia signaling pathway. We found that HIF1A overexpression was associated with higher mortality, independent of patient characteristics and other molecular variables. In contrast, EPAS1 expression was unrelated with clinical outcome. Our results suggest that HIF1A expression, but not EPAS1 expression, marks colorectal cancer with aggressive biological behavior.

Examining molecular changes or prognostic factors is important in cancer research. ${ }^{46-48}$ Studies examining the relation between HIF1A or EPAS1 expression and prognosis in colorectal cancer have yielded inconsistent results. HIF1A expression was associated with poor prog- nosis in some studies $\left(N=90,,^{26} N=135,,^{28}\right.$ and $N=$ $\left.60^{29}\right)$, whereas other studies $\left(N=87,27 N=101,{ }^{30}\right.$ and $N=74^{31}$ ) showed no independent prognostic value of HIF1A. Regarding EPAS1, one study $(N=87)^{27}$ showed its association with poor prognosis whereas another study $(N=90)^{26}$ did not. Our current findings are not in agreement with some of these previous results. This discrepancy might be due to a difference in the patient cohorts or the methods to assess HIF1A and EPAS1 expression or simply due to a chance variation between independent studies. All of the previous studies were limited by small sample sizes and low statistical power. Importance of large-scale studies cannot be emphasized enough, because small studies $(N<150)$ with null results have much higher likelihood of being unpublished than small studies with "significant" results, leading to publication bias. In contrast to the prior investigations, our study examined these HIF1A and EPAS1 expressions in a much larger cohort of stage I-IV colorectal cancers. In addition, we assessed the effect of HIF expression independent of other molecular events that have been documented to be critical in colorectal carcinogenesis.

The function of HIF1A is multifaceted and can be oncogenic or tumor-suppressive in a tumor type-specific fashion. ${ }^{49}$ In colorectal cancer, HIF1A appears to play an "oncogenic" role via distinct mechanisms. Tumor angiogenesis is critical for colorectal cancer development and progression. It is well established that tissue hypoxia and

Table 5. Stage-Specific Analysis of Patient Mortality in HIF1A-Positive Colorectal Cancer Compared with HIF1A-Negative Colorectal Cancer

\begin{tabular}{|c|c|c|c|c|c|c|}
\hline \multirow[b]{2}{*}{ Tumor stage } & \multicolumn{3}{|c|}{$\begin{array}{l}\text { Colorectal cancer-specific mortality in HIF1A-positive } \\
\text { tumors (vs. HIF1A-negative tumors as a referent) }\end{array}$} & \multicolumn{3}{|c|}{$\begin{array}{l}\text { Overall mortality in HIF1A-positive tumors } \\
\text { (vs. HIF1A-negative tumors as a referent) }\end{array}$} \\
\hline & $\begin{array}{c}\text { Number of deaths/cases } \\
\text { (HIF1A-positive versus } \\
\text { HIF1A-negative) }\end{array}$ & $\begin{array}{l}\text { Univariate HR } \\
\qquad(95 \% \mathrm{Cl})\end{array}$ & $\begin{array}{c}\text { Multivariate } \\
\text { HR } \\
(95 \% \mathrm{Cl})\end{array}$ & $\begin{array}{c}\text { Number of deaths/cases } \\
\text { (HIF1A-positive versus } \\
\text { HIF1A-negative) }\end{array}$ & $\begin{array}{l}\text { Univariate HR } \\
\qquad(95 \% \mathrm{Cl})\end{array}$ & $\begin{array}{c}\text { Multivariate } \\
\text { HR } \\
(95 \% \mathrm{Cl})\end{array}$ \\
\hline Stage I & $4 / 20$ vs. $16 / 140$ & $1.73(0.58-5.18)$ & $1.55(0.46-5.17)$ & $9 / 20$ vs. $40 / 140$ & $1.46(0.70-3.02)$ & $1.73(0.80-3.75)$ \\
\hline Stage II & $10 / 42$ vs. $22 / 180$ & $2.06(0.97-4.36)$ & $2.03(0.91-4.54)$ & $21 / 42$ vs. $61 / 180$ & $1.40(0.85-2.31)$ & $1.38(0.82-2.34)$ \\
\hline Stage III & $14 / 43$ vs. $43 / 157$ & $1.21(0.66-2.22)$ & $1.12(0.60-2.10)$ & $21 / 43$ vs. $67 / 157$ & $1.19(0.73-1.96)$ & $1.15(0.69-1.92)$ \\
\hline Stage IV & $31 / 31$ vs. $70 / 77$ & $1.94(1.23-3.06)$ & $1.88(1.17-3.02)$ & $31 / 31$ vs. $71 / 77$ & $1.94(1.23-3.06)$ & $1.88(1.17-3.03)$ \\
\hline $\begin{array}{l}\text { P for interaction } \\
\text { (HIF1A and stage) }\end{array}$ & & 0.43 & 0.35 & & 0.95 & 0.72 \\
\hline
\end{tabular}

The multivariate Cox regression model initially included HIF1A variable stratified by stage, age, year of diagnosis, sex, family history of colorectal cancer, BMI, tumor location, grade, mucinous component, and signet ring cell component. A backward stepwise elimination with a threshold of $P=0.20$ was used to select variables in the final model. 
HIF1A stimulate angiogenesis by up-regulating multiple proangiogenic factors, including VEGF. ${ }^{23,50,51}$ A study using colon cancer cells and xenografts has supported the role of HIF1A in cell proliferation and aerobic glycolysis. ${ }^{14}$ HIF1A has also been reported to promote colon cancer cell invasion by regulating proteins such as MMP2, cathepsin D, vimentin, or TGFA. ${ }^{12}$ Thus, HIF1A may affect several key steps in colon tumorigenesis, including angiogenesis, metabolism, proliferation, and invasion. ${ }^{49}$ Our observational results certainly support the "oncogenic" role of HIF1A in colorectal cancer. In addition, HIF1A has been reported to bind a hypoxiaresponsive element on the PTGS2 (COX-2) promoter and directly up-regulate PTGS2 expression, which facilitates colorectal cancer cell survival and angiogenesis. ${ }^{13}$ Our finding of the relationship between PTGS2 and HIF1A expression may be consistent with this experimental result. Further studies are necessary to examine the exact mechanism of HIF1A function on tumor behavior.

EPAS1 expression pattern and its clinical, pathological, molecular, and prognostic features in colorectal cancer are not well characterized. A previous study on colorectal cancer $(N=88)^{27}$ has shown that EPAS1 expression is related with high tumor grade $(P=0.0035)$ and poor prognosis $(P<0.05)$. Our current study showed no significant prognostic role of EPAS1 expression. Nonetheless, we did observe the inverse relation between EPAS1 expression and high tumor grade. In addition, EPAS1 expression was inversely associated with HIF1A expression. Our large-scale study at least suggests that these two isoforms, HIF1A and EPAS1, likely have distinctive expression patterns and biological functions in colorectal cancer. A recent study has shown that HIF1A and EPAS1 translation are differentially regulated by KRAS and BRAF in colon cancer. ${ }^{52}$ Further experimental studies are necessary to clarify the mechanisms that differentially regulate HIF1A and EPAS1 expression in colorectal cancer. Furthermore, our intriguing findings need to be confirmed by independent studies in the future.

There are currently no standardized methods to evaluate HIF expression by immunohistochemistry; nuclear expression, cytoplasmic expression, or the combined score with nuclear/cytoplasmic expression has been assessed in a variety of different ways. Although one may assume that nuclear HIF is the active form, HIF is synthesized in the cytoplasm, and HIF staining is clearly localized in the cytoplasm of cancer cells. ${ }^{53,54}$ In addition, strong cytoplasmic HIF expression (eg, positive expression in $\geq 50 \%$ tumor cells) has been reported to better reflect the HIF up-regulated pathway in paraffin-embedded specimens. ${ }^{55-57}$ Our method of assessing brisk cytoplasmic expression (ie, moderate staining in $\geq 50 \%$ of tumor cells or strong staining) also yielded a highly significant association between HIF1A expression and poor prognosis in colorectal cancer. Thus, strong cytoplasmic HIF staining may be a reasonable surrogate marker when one evaluates activation level of the HIF pathway in human cancers.

As a limitation of this study, data on cancer treatment were limited. Nonetheless, it is unlikely that chemother- apy use differed according to tumoral HIF1A or EPAS1 status, because such data were not available to patients or treating physicians. In addition, beyond cause of mortality, data on cancer recurrences were not available in these cohorts. Nonetheless, given the median survival for metastatic colorectal cancer was $\sim 10$ to 12 months during much of the time period of this study, colorectal cancer-specific mortality should be a reasonable surrogate for colorectal cancer-specific outcomes.

In summary, HIF1A expression in colorectal cancer is independently associated with poor prognosis. Although EPAS1 expression in colorectal cancer is not associated with clinical outcome, it is inversely associated with high tumor grade. Considering the HIF and related pathways as attractive therapeutic targets and interactions between the HIF and many other pathways, our findings may have considerable clinical implications. Future studies are needed to confirm our findings as well as to elucidate exact mechanisms that differentially regulate HIF1A and EPAS1 in colorectal cancer.

\section{Acknowledgment}

We deeply thank the Nurses' Health Study and Health Professionals Follow-up Study cohort participants who have generously agreed to provide us with biological specimens and information through responses to questionnaires.

\section{References}

1. Bertout JA, Patel SA, Simon MC: The impact of $\mathrm{O}_{2}$ availability on human cancer. Nat Rev Cancer 2008, 8:967-975

2. Wouters BG, Koritzinsky M: Hypoxia signalling through mTOR and the unfolded protein response in cancer. Nat Rev Cancer 2008, 8:851-864

3. Erler JT, Bennewith KL, Nicolau M, Dornhofer N, Kong C, Le QT, Chi JT, Jeffrey SS, Giaccia AJ: Lysyl oxidase is essential for hypoxiainduced metastasis. Nature 2006, 440:1222-1226

4. Narita T, Yin S, Gelin CF, Moreno CS, Yepes M, Nicolaou KC, Van Meir EG: Identification of a novel small molecule $\mathrm{HIF}-1 \alpha$ translation inhibitor. Clin Cancer Res 2009, 15:6128-6136

5. Koh MY, Spivak-Kroizman TR, Powis G: Inhibiting the hypoxia response for cancer therapy: the new kid on the block. Clin Cancer Res 2009, 15:5945-5946

6. Kaelin WG, Jr: The von Hippel-Lindau tumour suppressor protein: $\mathrm{O}_{2}$ sensing and cancer. Nat Rev Cancer 2008, 8:865-873

7. Yee Koh M, Spivak-Kroizman TR, Powis G: HIF-1 regulation: not so easy come, easy go. Trends Biochem Sci 2008, 33:526-534

8. Zhong H, De Marzo AM, Laughner E, Lim M, Hilton DA, Zagzag D, Buechler P, Isaacs WB, Semenza GL, Simons JW: Overexpression of hypoxia-inducible factor $1 \alpha$ in common human cancers and their metastases. Cancer Res 1999, 59:5830-5835

9. Talks KL, Turley H, Gatter KC, Maxwell PH, Pugh CW, Ratcliffe PJ, Harris AL: The expression and distribution of the hypoxia-inducible factors HIF- $1 \alpha$ and HIF- $2 \alpha$ in normal human tissues, cancers, and tumor-associated macrophages. Am J Pathol 2000, 157:411-421

10. Wang V, Davis DA, Haque M, Huang LE, Yarchoan R: Differential gene up-regulation by hypoxia-inducible factor- $1 \alpha$ and hypoxia-inducible factor-2 $\alpha$ in HEK293T cells. Cancer Res 2005, 65:3299-3306

11. Aprelikova O, Wood M, Tackett S, Chandramouli GV, Barrett JC: Role of ETS transcription factors in the hypoxia-inducible factor-2 target gene selection. Cancer Res 2006, 66:5641-5647

12. Krishnamachary B, Berg-Dixon S, Kelly B, Agani F, Feldser D, Ferreira G, lyer N, LaRusch J, Pak B, Taghavi P, Semenza GL: Regulation of colon 
carcinoma cell invasion by hypoxia-inducible factor 1. Cancer Res 2003, 63:1138-1143

13. Kaidi A, Qualtrough D, Williams AC, Paraskeva C: Direct transcriptional up-regulation of cyclooxygenase-2 by hypoxia-inducible factor (HIF)-1 promotes colorectal tumor cell survival and enhances HIF-1 transcriptional activity during hypoxia. Cancer Res 2006, 66:6683-6691

14. Dang DT, Chen F, Gardner LB, Cummins JM, Rago C, Bunz F, Kantsevoy SV, Dang LH: Hypoxia-inducible factor- $1 \alpha$ promotes nonhypoxia-mediated proliferation in colon cancer cells and xenografts. Cancer Res 2006, 66:1684-1693

15. Ryan HE, Poloni M, McNulty W, Elson D, Gassmann M, Arbeit JM, Johnson RS: Hypoxia-inducible factor- $1 \alpha$ is a positive factor in solid tumor growth. Cancer Res 2000, 60:4010-4015

16. Carmeliet P, Dor Y, Herbert JM, Fukumura D, Brusselmans K, Dewerchin M, Neeman M, Bono F, Abramovitch R, Maxwell P, Koch CJ, Ratcliffe P, Moons L, Jain RK, Collen D, Keshert E: Role of HIF- $1 \alpha$ in hypoxiamediated apoptosis, cell proliferation and tumour angiogenesis. Nature 1998, 394:485-490

17. Scortegagna M, Martin RJ, Kladney RD, Neumann RG, Arbeit JM: Hypoxia-inducible factor $-1 \alpha$ suppresses squamous carcinogenic progression and epithelial-mesenchymal transition. Cancer Res 2009, 69:2638-2646

18. Sowter HM, Ratcliffe PJ, Watson P, Greenberg AH, Harris AL: HIF-1dependent regulation of hypoxic induction of the cell death factors BNIP3 and NIX in human tumors. Cancer Res 2001, 61:6669-6673

19. Goda N, Ryan HE, Khadivi B, McNulty W, Rickert RC, Johnson RS: Hypoxia-inducible factor $1 \alpha$ is essential for cell cycle arrest during hypoxia. Mol Cell Biol 2003, 23:359-369

20. Holmquist-Mengelbier L, Fredlund E, Lofstedt T, Noguera R, Navarro S, Nilsson H, Pietras A, Vallon-Christersson J, Borg A, Gradin K, Poellinger L, Pahlman S: Recruitment of HIF- $1 \alpha$ and HIF-2 $\alpha$ to common target genes is differentially regulated in neuroblastoma: hIF-2 $\alpha$ promotes an aggressive phenotype. Cancer Cell 2006, 10:413-423

21. Kondo K, Kim WY, Lechpammer M, Kaelin WG, Jr: Inhibition of HIF2a is sufficient to suppress PVHL-defective tumor growth. PLoS Biol 2003, 1:E83

22. Raval RR, Lau KW, Tran MG, Sowter HM, Mandriota SJ, Li JL, Pugh CW, Maxwell PH, Harris AL, Ratcliffe PJ: Contrasting properties of hypoxia-inducible factor 1 (HIF-1) and HIF-2 in von Hippel-Lindauassociated renal cell carcinoma. Mol Cell Biol 2005, 25:5675-5686

23. Imamura $T$, Kikuchi H, Herraiz MT, Park DY, Mizukami $Y$, MinoKenduson M, Lynch MP, Rueda BR, Benita Y, Xavier RJ, Chung DC: $\mathrm{HIF-} 1 \alpha$ and $\mathrm{HIF}-2 \alpha$ have divergent roles in colon cancer. Int $\mathrm{J}$ Cancer 2009, 124:763-771

24. Acker T, Diez-Juan A, Aragones J, Tjwa M, Brusselmans K, Moons L, Fukumura D, Moreno-Murciano MP, Herbert JM, Burger A, Riedel J, Elvert G, Flamme I, Maxwell PH, Collen D, Dewerchin M, Jain RK, Plate KH, Carmeliet P: Genetic evidence for a tumor suppressor role of HIF-2 $\alpha$. Cancer Cell 2005, 8:131-141

25. Favier J, Lapointe S, Maliba R, Sirois MG: HIF2 $\alpha$ reduces growth rate but promotes angiogenesis in a mouse model of neuroblastoma. BMC Cancer 2007, 7:139

26. Rasheed S, Harris AL, Tekkis PP, Turley H, Silver A, McDonald PJ, Talbot IC, Glynne-Jones R, Northover JM, Guenther T: Hypoxiainducible factor- $1 \alpha$ and $-2 \alpha$ are expressed in most rectal cancers but only hypoxia-inducible factor- $1 \alpha$ is associated with prognosis. $\mathrm{Br} J$ Cancer 2009, 100:1666-1673

27. Yoshimura H, Dhar DK, Kohno H, Kubota H, Fujii T, Ueda S, Kinugasa $\mathrm{S}$, Tachibana M, Nagasue N: Prognostic impact of hypoxia-inducible factors $1 \alpha$ and $2 \alpha$ in colorectal cancer patients: correlation with tumor angiogenesis and cyclooxygenase-2 expression. Clin Cancer Res 2004, 10:8554-8560

28. Schmitz KJ, Muller $\mathrm{Cl}$, Reis $\mathrm{H}$, Alakus H, Winde G, Baba HA Wohlschlaeger J, Jasani B, Fandrey J, Schmid KW: Combined analysis of hypoxia-inducible factor $1 \alpha$ and metallothionein indicates an aggressive subtype of colorectal carcinoma. Int $\mathrm{J}$ Colorectal Dis 2009, 24:1287-1296

29. Rajaganeshan R, Prasad R, Guillou PJ, Scott N, Poston G, Jayne DG: Expression patterns of hypoxic markers at the invasive margin of colorectal cancers and liver metastases. Eur J Surg Oncol 2009, 35:1286-1294

30. Kuwai T, Kitadai Y, Tanaka S, Onogawa S, Matsutani N, Kaio E, Ito M, Chayama K: Expression of hypoxia-inducible factor- $1 \alpha$ is associated with tumor vascularization in human colorectal carcinoma. Int $\mathrm{J}$ Cancer 2003, 105:176-181

31. Furlan D, Sahnane N, Carnevali I, Cerutti R, Bertoni F, Kwee I, Uccella S, Bertolini V, Chiaravalli AM, Capella C: Up-regulation of the hypoxiainducible factor-1 transcriptional pathway in colorectal carcinomas. Hum Pathol 2008, 39:1483-1494

32. Chan AT, Ogino S, Fuchs CS: Aspirin and the risk of colorectal cancer in relation to the expression of COX-2. N Engl J Med 2007, 356:2131-2142

33. Ogino S, Nosho K, Kirkner GJ, Kawasaki T, Meyerhardt JA, Loda M, Giovannucci EL, Fuchs CS: CpG island methylator phenotype, microsatellite instability, BRAF mutation and clinical outcome in colon cancer. Gut 2009, 58:90-96

34. Ogino S, Nosho K, Kirkner GJ, Kawasaki T, Chan AT, Schernhammer ES, Giovannucci EL, Fuchs CS: A cohort study of tumoral LINE-1 hypomethylation and prognosis in colon cancer. J Natl Cancer Inst 2008, 100:1734-1738

35. Ogino S, Kawasaki T, Kirkner GJ, Kraft P, Loda M, Fuchs CS: Evaluation of markers for $\mathrm{CpG}$ island methylator phenotype (CIMP) in colorectal cancer by a large population-based sample. J Mol Diagn 2007, 9:305-314

36. Ogino S, Kawasaki T, Brahmandam M, Yan L, Cantor M, Namgyal C, Mino-Kenudson M, Lauwers GY, Loda M, Fuchs CS: Sensitive sequencing method for KRAS mutation detection by Pyrosequencing. $J$ Mol Diagn 2005, 7:413-421

37. Ogino S, Kawasaki T, Kirkner GJ, Loda M, Fuchs CS: CpG island methylator phenotype-low (CIMP-low) in colorectal cancer: possible associations with male sex and KRAS mutations. J Mol Diagn 2006, 8:582-588

38. Nosho K, Kawasaki T, Ohnishi M, Suemoto Y, Kirkner GJ, Zepf D, Yan L, Longtine JA, Fuchs CS, Ogino S: PIK3CA mutation in colorectal cancer: relationship with genetic and epigenetic alterations. Neoplasia 2008, 10:534-541

39. Ogino S, Brahmandam M, Cantor M, Namgyal C, Kawasaki T, Kirkner G, Meyerhardt JA, Loda M, Fuchs CS: Distinct molecular features of colorectal carcinoma with signet ring cell component and colorectal carcinoma with mucinous component. Mod Pathol 2006, 19:59-68

40. Ogino S, Kawasaki T, Brahmandam M, Cantor M, Kirkner GJ, Spiegelman D, Makrigiorgos GM, Weisenberger DJ, Laird PW, Loda M, Fuchs CS: Precision and performance characteristics of bisulfite conversion and real-time PCR (MethyLight) for quantitative DNA methylation analysis. J Mol Diagn 2006, 8:209-217

41. Ogino S, Cantor M, Kawasaki T, Brahmandam M, Kirkner GJ Weisenberger DJ, Campan M, Laird PW, Loda M, Fuchs CS: CpG island methylator phenotype (CIMP) of colorectal cancer is best characterised by quantitative DNA methylation analysis and prospective cohort studies. Gut 2006, 55:1000-1006

42. Weisenberger DJ, Siegmund KD, Campan M, Young J, Long TI, Faasse MA, Kang GH, Widschwendter M, Weener D, Buchanan D, Koh H, Simms L, Barker M, Leggett B, Levine J, Kim M, French AJ, Thibodeau SN, Jass J, Haile R, Laird PW: CpG island methylator phenotype underlies sporadic microsatellite instability and is tightly associated with BRAF mutation in colorectal cancer. Nat Genet 2006, 38:787-793

43. Ogino S, Kawasaki T, Nosho K, Ohnishi M, Suemoto Y, Kirkner GJ, Fuchs CS: LINE-1 hypomethylation is inversely associated with microsatellite instability and $\mathrm{CpG}$ island methylator phenotype in colorectal cancer. Int J Cancer 2008, 122:2767-2773

44. Ogino S, Brahmandam M, Kawasaki T, Kirkner GJ, Loda M, Fuchs CS: Combined analysis of COX-2 and p53 expressions reveals synergistic inverse correlations with microsatellite instability and $\mathrm{CpG}$ island methylator phenotype in colorectal cancer. Neoplasia 2006 8:458-464

45. Ogino S, Kawasaki T, Kirkner GJ, Yamaji T, Loda M, Fuchs CS: Loss of nuclear p27 (CDKN1B/KIP1) in colorectal cancer is correlated with microsatellite instability and CIMP. Mod Pathol 2007, 20:15-22

46. van der Bilt JD, Soeters ME, Duyverman AM, Nijkamp MW, Witteveen $\mathrm{PO}$, van Diest PJ, Kranenburg O, Borel Rinkes IH: Perinecrotic hypoxia contributes to ischemia/reperfusion-accelerated outgrowth of colorectal micrometastases. Am J Pathol 2007, 170:1379-1388

47. Plumb CL, Adamcic U, Shahrzad S, Minhas K, Adham SA, Coomber BL: Modulation of the tumor suppressor protein $\alpha$-catenin by ischemic microenvironment. Am J Pathol 2009, 175:1662-1674

48. Kuwai T, Nakamura T, Kim SJ, Sasaki T, Kitadai Y, Langley RR, Fan D, 
Hamilton SR, Fidler IJ: Intratumoral heterogeneity for expression of tyrosine kinase growth factor receptors in human colon cancer surgical specimens and orthotopic tumors. Am J Pathol 2008, 172:358-366

49. Rankin EB, Giaccia AJ: The role of hypoxia-inducible factors in tumorigenesis. Cell Death Differ 2008, 15:678-685

50. Mizukami Y, Li J, Zhang X, Zimmer MA, lliopoulos O, Chung DC: Hypoxia-inducible factor-1-independent regulation of vascular endothelial growth factor by hypoxia in colon cancer. Cancer Res 2004 64:1765-1772

51. Fukuda R, Kelly B, Semenza GL: Vascular endothelial growth factor gene expression in colon cancer cells exposed to prostaglandin $E_{2}$ is mediated by hypoxia-inducible factor 1. Cancer Res 2003, 63:2330-2334

52. Kikuchi H, Pino MS, Zeng M, Shirasawa S, Chung DC: Oncogenic KRAS and BRAF differentially regulate hypoxia-inducible factor- $1 \alpha$ and $-2 \alpha$ in colon cancer. Cancer Res 2009, 69:8499-8506

53. Kuwai T, Kitadai $\mathrm{Y}$, Tanaka S, Hiyama T, Tanimoto K, Chayama K: Mutation of the von Hippel-Lindau (VHL) gene in human colorectal carcinoma: association with cytoplasmic accumulation of hypoxiainducible factor (HIF)-1 $\alpha$. Cancer Sci 2004, 95:149-153

54. Nanni S, Benvenuti V, Grasselli A, Priolo C, Aiello A, Mattiussi S, Colussi C, Lirangi V, Illi B, D'Eletto M, Cianciulli AM, Gallucci M, De
Carli P, Sentinelli S, Mottolese M, Carlini P, Strigari L, Finn S, Mueller E, Arcangeli G, Gaetano C, Capogrossi MC, Donnorso RP, Bacchetti S, Sacchi A, Pontecorvi A, Loda M, Farsetti A: Endothelial NOS, estrogen receptor $\beta$, and HIFs cooperate in the activation of a prognostic transcriptional pattern in aggressive human prostate cancer. J Clin Invest 2009, 119:1093-1108

55. Giatromanolaki A, Koukourakis MI, Sivridis E, Turley H, Talks K, Pezzella F, Gatter KC, Harris AL: Relation of hypoxia inducible factor $1 \alpha$ and $2 \alpha$ in operable non-small cell lung cancer to angiogenic/molecular profile of tumours and survival. $\mathrm{Br} J$ Cancer 2001, 85:881-890

56. Sivridis E, Giatromanolaki A, Gatter KC, Harris AL, Koukourakis MI: Association of hypoxia-inducible factors $1 \alpha$ and $2 \alpha$ with activated angiogenic pathways and prognosis in patients with endometrial carcinoma. Cancer 2002, 95:1055-1063

57. Koukourakis MI, Bentzen SM, Giatromanolaki A, Wilson GD, Daley FM, Saunders MI, Dische S, Sivridis E, Harris AL: Endogenous markers of two separate hypoxia response pathways (hypoxia inducible factor $2 \alpha$ and carbonic anhydrase 9) are associated with radiotherapy failure in head and neck cancer patients recruited in the CHART randomized trial. J Clin Oncol 2006, 24:727-735 